\title{
Essence of Antibody Generation and Autoimmunity
}

\author{
Charles Edward Ng'Hwaya Masule \\ Institute of Mechanical Engineering, Mechanical Process Engineering and Environmental Technology, Dresden University of Technology, \\ Dresden, Germany
}

Email address:

nghwaya@yahoo.co.uk, c.e.masule@gmail.com

\section{To cite this article:}

Charles Edward Ng'Hwaya Masule. Essence of Antibody Generation and Autoimmunity. International Journal of Immunology. Vol. 7, No. 1, 2019, pp. 1-4. doi: 10.11648/j.iji.20190701.11

Received: January 4, 2019; Accepted: January 31, 2019; Published: March 6, 2019

\begin{abstract}
Because of the belief that lactic acid plays a role in the generation of antibodies in the muscles in humans, the aim of this study had been to establish the structure and the proper designation for the pair of anantiomers of lactic acid and for the peptide chain for distinct pathways in the generation of beneficial and destructive antibodies and to support the belief by inducing immunity against the scorpion's poison in humans and mice. I had to designate the structures for the pair of anantiomers of lactic acid and for the protein's peptide chain by adopting Emil Fischer's naming convention for glucose in terms of the "D-" and "L-" name prefixes and thereupon develop an approach of uniquely marring the anantiomers in the "D-" to "L-" fashion and vice versa. I had to cause a scorpion's bite on my right knee and another bite on my $1^{\text {st }}$ toe of the right foot 28 days after the $1^{\text {st }}$ bite. I had injected a plain solution of scorpion's poison of 2 bite-equivalent units in mice in the first instance and I added D-lactic acid to the replica of the same in the second instance. D-(+)-lactic acid will refer to the lactic acid which is produced in the muscles of humans and other mammals, whereas L-(-)-lactic acid will refer to a mirror image of D(+)-lactic acid which might be produced by lactic acid bacteria via fermentation and might also be chemically synthesized. The D-(+)-peptide chain found in humans and other mammals has its mirror image, the L-(+)-peptide chain, in pathogens. The effect of the scorpion's bite on the knee subsided after 24 hours whereas the repeated bite on the $1^{\text {st }}$ toe of the foot 28 days since the first bite went without trouble. The group of mice which received a shot of a plain solution of scorpion's poison virtually paralyzed thereupon for 24 hours whereas the group which received the replica of the same mixed with D-lactic acid went unaffected during the observation. An antigen and its corresponding neutralizing antibody make a pair of anantiomers linked via a sugar-bridge. D-lactic acid must combine with the antigen's L-peptide chain for beneficial antibodies whereas Llactic acid must combine with the innocent D-peptide chain for destructive antibodies in autoimmunity but beneficial against tumors and cancer cells. The pancreas and the tissues of the muscles in humans have local capability to generate antibodies of global effect.
\end{abstract}

Keywords: AIDS, Antigen, Antibody, Cancer, HIV, Immunity, Malaria, Plasmodium, Diabetes, Rheumatoid, Arthritis

\section{Introduction}

\subsection{Background}

Whereas it is well settled in the field of health care that physical exercising considerably contributes to foster good mental and physical health as well as contributes to foster defense against invading pathogens in humans, there exists no proof to associate physical exercising and acquired immunity against malaria and other infectious diseases. Whereas the belief of cumulative building-up of antibodies in the body given a progressive exposure to the malaria parasites with increasing age in humans is well established
$[2,10]$, there are also reports which associate sustainable and fully protective immunity against the malaria with the use of combo chemoprophylaxis with chloroquine and the so-called "controlled human malaria infections" [1]. Other views: Genetic factors are being attributed to the big proportion of the variability in malaria incidence among inhabitants in malaria endemic areas [3]. Acquisition of immunity to malaria may be biphasic with immunity to disease being actually acquired before immunity to infection [8-9].

Whereas the production of lactic acid from glycogen 
during glycolysis in muscles of humans during physical efforts is well documented [4-7], nothing exists in documentation in respect of any incidental benefits therefrom to the immune system and to the human body at large whereas the enzyme catalyzed cleavage of glycogen will produce D-glucose on metabolic demand [4-7].

Because of the non-deterministic nature of the pathway leading to the acquired immunity against malaria and because of the belief that lactic acid plays a role in the generation of antibodies locally in the muscles in humans, the $1^{\text {st }}$ aim of this study had been to establish the structure and the proper designation for a non-superimposable pair of anantiomers for lactic acid and for the peptide chain such that the route for the antibody generation in respect of the beneficial antibodies can be distinguished from the route for the generation of the adverse antibodies responsible for the autoimmunity, whereas the $2^{\text {nd }}$ aim had been to improvise an experiment to induce immunity against the scorpion's poison in humans in support of the belief and thereupon to explain the dependency of the generation of autoimmunity upon local variables in respect of diabetes 1 and rheumatoid arthritis, whereas the $3^{\text {rd }}$ aim had been to find out the potential of lactic acid in the neutralization of the scorpion's poison in mice in support of the belief.

\subsection{Methods}

I had to designate the structure for the pair of anantiomers of lactic acid by adopting Emil Fischer's naming convention for glucose in terms of the "D-" and "L-" name prefixes [47]. Emil Fischer holds to be the father of the chemistry of glucose [4-7].

I had to determine the mirror image for the basic structure of the protein's peptide chain and appropriately adopt the "D-" and "L-" prefixes for the names of that pair in analogy to the designation of glucose and develop an approach of uniquely marring the anantiomers of lactic acid to the peptide chain in the "D-" to "L-" fashion and vice versa.

In support of the belief: I had to cause a bite from a scorpion of the common type in Dar-Es-salaam of Tanzania on my right knee and to sufficiently perform light jogging and walking exercises during the 24 hours after the bite. Subsequently, I had to cause another bite on my $1^{\text {st }}$ toe of the right foot 28 days after the $1^{\text {st }}$ bite to qualitatively evaluate the presence of a potent immune response against the scorpion's poison in my body.

Also in support of the belief I had pursued the potential of D-lactic acid to neutralize scorpion's poison in mice: I had to collect scorpion poison from 20 scorpions of the common type in Dar-Es-salaam of Tanzania by provoking 20 scorpion bites (scorpion shots) on a small soft tissue paper at $10^{\circ} \mathrm{C}$. I had subjected the tissue to steep in $12 \mathrm{ml}$ of distilled water in a test tube at $10^{\circ} \mathrm{C}$ for $10 \mathrm{~min}$ under mixing followed by filtration via a vacuum filter thereby making a final filtrate of $8 \mathrm{ml}$ having about 16 biteequivalent units and then separated the filtrate into two samples of $4 \mathrm{ml}$ each under the names "hot shot" and "neutral shot". To the "neutral shot" I added drops of previously prepared $1 \mathrm{~g} / \mathrm{lt} \mathrm{D}$-lactic acid solution such that the sample reached the $5 \mathrm{ml}$ level and left the sample to stay for 24 hours at $10^{\circ} \mathrm{C}$. I had given $1 \mathrm{ml}$ of red shot to each of the 4 mice painted red and $1 \mathrm{ml}$ of neutral shot to each of the 4 mice painted green.

\section{Literature Survey}

\subsection{Glycogen}

Glycogen is the carbohydrate packet for storage in animals [4-7]. It is a descendant of amylopectin in terms of structure resemblance in a hierarchy stemming from amylase [4-7]. Amylose and amylopectin make starch in a composition of $20 \%$ and $80 \%$ respectively [4-7].

The enzymatic conversion of glycogen to lactic acid during glycolysis is said to be a reversible process [4-7], thus:

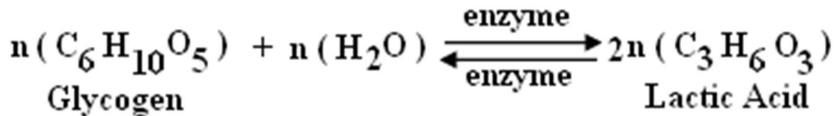

Figure 1. Enzymatic Conversion of Glycogen into Lactic Acid.

The enzymatic breaking down of glycogen releases glucose on demand [4-7], thus:

$$
\underset{\text { Glycogen }}{\mathrm{n}\left(\mathrm{C}_{6} \mathrm{H}_{10} \mathrm{O}_{5}\right.}+\mathrm{n}\left(\mathrm{H}_{2} \mathrm{O}\right) \stackrel{\text { enzyme }}{\longrightarrow} \underset{\text { Glucose }}{\left(\mathrm{C}_{6} \mathrm{H}_{12} \mathrm{O}_{6}\right)}
$$

Figure 2. Enzymatic conversion of Glycogen into Glucose.

\subsection{Proteins and the Peptide Chain}

In terms of the primary structure: proteins are made up of peptide chains which are a result of amino acid residues joined by amide linkages [4-7], thus:

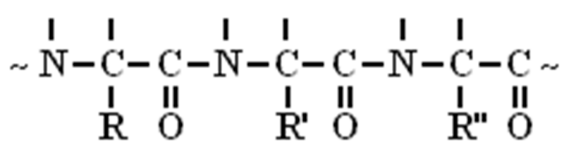

Figure 3. Structure of the Peptide Chain.

Where R, R' and R" are side chains depending upon the structure of the particular amino acid residue.

\section{Approach}

\subsection{Adopting the Naming Convention for the Pair of Anantiomers of Lactic Acid}

As far as the structure of lactic acid is concerned: the "D-" and "L-" designations of glucose will analogously be used to differentiate the two members of that pair of anantiomers. The hydroxyl group must be on the right hand side in Dlactic acid, thus: 


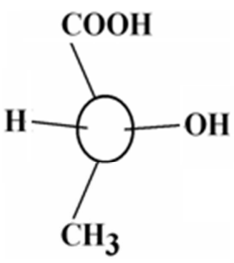

D-(+)-Lactic Acid

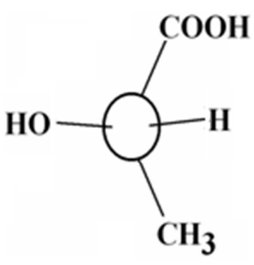

L-(-)-Lactic Acid
Figure 4. Structure of the Anantiomer Pair of Lactic Acid.

Since D-(+)-lactic acid is known to be produced in the muscles of humans [4-7], the other anantiomer of that pair, L-(-)-lactic acid, must therefore get into the body of humans through ingestion or intravenous injection. L-(-)-lactic acid therefore refers to a grade out of anaerobic fermentation via lactic acid bacteria and to a chemically synthesized grade.

\subsection{Structure of the Peptide Chain and the Naming Convention}

By proceeding in the way of Emil Fischer's reasoning [47], I had given the name D-(+)-peptide chain to the peptide chain occurring in animal proteins. The " $R$ " group must be on the right hand side in the D-(+)-peptide chain, thus:

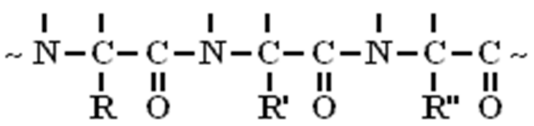

$$
\begin{aligned}
& \text { D-(+)-Peptide Chain }
\end{aligned}
$$

Figure 5. Structure of the D-(+)-Peptide Chain.

That is to say: antibodies and enzymes found in the body of an animal must be made up of the D-peptide chain.

I had assumed the mirror image to for the D-(+)-peptide chain to be the peptide chain occurring in pathogen's proteins (also known as antigen's proteins) thus:

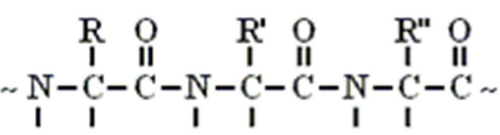

$$
\begin{aligned}
& \text { L-(-)-Peptide Chain }
\end{aligned}
$$

The critical assumption here is that the carbon atoms linked to the amino acid residues are chiral. That is to say: although there are several thousand structures of the peptide chain possible, the naturally occurring peptide chains in mammals are limited.

\subsection{Linking of the Peptide Chain to Lactic Acid}

The critical assumption is that: D-lactic acid cannot combine with a D-peptide chain but with a L-peptide chain to trigger the generation of beneficial antibodies whereas Llactic acid can only combine with a D-peptide chain to trigger the adverse effect of autoimmunity.

That is to say: for a beneficial antibody to be produced, at least two molecules of D-lactic acid molecules must get attached to the L-peptide chain as if a D-glucose molecule were being attached at once. In order to have a complete antibody the sugar end of the neutralized L-peptide chain must be linked to an anantiomer of the L-peptide chain, a Dpeptide chain, before the stencil (the L-peptide chain) gets detached for the process to repeat until the equilibrium is reached.

For the building-up of the adverse autoimmunity in mammals L-lactic acid must link to the D-peptide chain.

\section{Results}

\subsection{Scorpion Bite on the Knee}

The bitten knee didn't swell after the scorpion's bite onwards and the feeling of the effect of the bite was restricted just to the front side of the knee. It had taken me about 24 hours since the bite for the feeling in the knee to get to normal. One feels the area around the bitten site to be in a state of turmoil and somewhat with the lack of sensory. I had caused the repeated bite on the $1^{\text {st }}$ toe of my right foot after 28 days since the first bite of $4^{\text {th }}$ December 2018 . The $2^{\text {nd }}$ bite did not bring any troubles.

\subsection{Scorpion Test with Mice}

The group of mice which received a shot of a plain solution of scorpion's poison in injection virtually paralyzed soon after the shot and stayed in that state for 24 hours whereas the group which received a mixture of Dlactic acid and the poison in injection did not show any sign of discomfort during the 36 hours of observation.

\section{Discussion}

\subsection{Acquired Immunity Against Malaria}

Although without quantitative proof I believe to have acquired immunity against the malaria parasite because my last case of malaria was treated in Dar-Es-salaam in October 2007 at an age of 44 in Dar-Es-Salaam, Tanzania, by administering pyrimethamine-sulphadoxine alongside the intake of sufficient glucose solution and fruit juices as well as a taking of walking exercises. The mere assumption that antibodies build up against the parasite stage-wise in the cause of exposure to the parasite with increasing age fails on the fact that my last case of malaria came after my stay of about 14 years in Europe. I rather believe in the likelihood of the successful linking of D-lactic acid to the malaria parasite's antigen during my last case of malaria.

\subsection{Acquired Immunity Against the Scorpion Poison}

Like in the case of malaria I don't believe in the cumulative building-up of the antibodies against the scorpion's poison out of my previous bites on the left rib side and on my toes, but rather believe in the building up of the antibodies through the D-lactic acid pathway via the bite on my right knee. 


\subsection{Scorpion Poison in Mice}

It can strongly be argued qualitatively that D-lactic acid contributed to neutralize the scorpion's poison for the test with mice under the combo solution injections of the poison and D-lactic acid for the observed lack of the poison's effect to the mice in contrast to the case of plane poison's solution injections which virtually paralyzed the mice under test.

\section{Conclusion}

An antigen and its corresponding neutralizing antibody make a pair of anantiomers linked via a sugar bridge.

D-lactic acid combines with the antigen's L-peptide chain for the generation of beneficial antibodies in humans whereas L-lactic acid combines with the innocent D-peptide chain for the generation of the adverse autoimmunity in diabetes 1 and rheumatoid arthritis and likewise L-lactic acid must combine with a malignant D-peptide chain for the generation of antibodies against tumors and cancer cells.

The tissues of the muscles of the knee in humans have local capability to generate antibodies against the poison of the scorpion although the immunity so generated showed a global effect in nature and so should the pancreas behave by inference.

Neutralization capability against the scorpion's poison was observed in mice under the injections of a combo solution of the poison and D-lactic acid.

The non-deterministic factor in the generation of immunity against the malaria parasite in humans must be thought in the line of local capability of a tissue to generate the neutralizing antibodies therefor.

\section{References}

[1] Bijker, E. M. and Sauerwein, R. W.: Enhancement of naturally acquired immunity against malaria by drug use, Journal of Medical Microbiology (2012), 61, 904-910 DOI 10.1099/jmm.0.041277-0.

[2] Doolan, D. L., Dobaño, C. and Baird, J. K.: Acquired Immunity to Malaria, Clinical Microbiology Reviews (2009) Jan; 22(1): 13-36. doi: 10.1128/CMR.00025-08 PMCID: PMC2620631 PMID: 19136431

[3] Mackinnon, M. J., Mwangi, T. W., Snow, R. W., Marsh, K. and Williams, T. N.: Heritability of Malaria in Africa, PLoS Med (2005), 2(12): e340.

[4] Morrison, R. T. and Boyd, R. N.: Organic Chemistry, $3^{\text {rd }}$ Edition (Allan and Bacon Inc.: London, 1973).

[5] Morrison, R. T. and Boyd, R. N.: Organic Chemistry, $4^{\text {th }}$ Edition (Allan and Bacon Inc.: London, 1983).

[6] Morrison, R. T. and Boyd, R. N.: Organic Chemistry, $5^{\text {th }}$ Edition (Allan and Bacon Inc.: London, 1987).

[7] Morrison, R. T. and Boyd, R. N.: Organic Chemistry, $6^{\text {th }}$ Edition (Prentice Hall: New Jersey, 1992).

[8] Roca-Feltrer, A., Carneiro, I., Smith, L., Schellenberg, J. R., Greenwood, B. and Schellenberg, D.: The Age Patterns of Severe Malaria Syndromes in Sub-Saharan Africa across a Range of Transmission Intensities and Seasonality Settings, Malar J (2010), 9: 282

[9] Snow, R. W., Bastos de Azevedo, I., Lowe, B. S., Kabiru, E. W., Nevill, C. G., Mwankusye, S., Kassiga, G., Marsh, K. and Teuscher, T.: Severe Childhood Malaria in two Areas of markedly different Falciparum Transmission in East Africa. Acta Trop (1994), 57(4): 289-300.

[10] SOON, T. H. and ENG, T. P.: Treatment Failure of Falciparum Malaria with Fansidar in Tawau Sabah, January June 1982, Med. J. Malaysia Vol. 38 No. 3 September 1983. 